\title{
“ESCUCHA, ENTONCES, UN SUEÑO POR OTRO”. ANTÍSTENES EN EL TEETETO DE PLATÓN
}

\author{
Claudia Mársico \\ Universidad de Buenos Aires - CONICET / ANCBA \\ claudiamarsico@gmail.com
}

\begin{abstract}
RESUMEN / ABSTRACT
El avance de los estudios sobre filosofías socráticas ha permitido una vuelta renovada al examen de pasajes intertextuales en el corpus platónico. El presente trabajo explora pasaje del sueño de Teeteto, 201c ss. y sus vínculos con la filosofía antisténica. En primer lugar, analiza las características de esta obra en el contexto del diálogo socrático. En segundo lugar, traza las coordenadas exegéticas del pasaje del sueño, y finalmente, ofrece una interpretación de la filosofía antisténica que revela contactos relevantes con el planteo platónico. Por esta vía, se despliega una hipótesis sobre el sentido general del diálogo y su modo de comprender el fenómeno del conocimiento.
\end{abstract}

Palabras Clave: Platón, Antístenes, sueño, conocimiento, opinión.

\section{"LISTEN MY DREAM IN EXCHANGE OF YOUR DREAM".}

Antisthenes in Plato's Theaetetus

The development of the studies on the Socratic philosophies have enabled a return to the analysis of intertextual passages within the platonic corpus. This work explores the dream passage in Theaetetus, 201c ff. and its links with Antisthenic philosophy. Firstly, it analyses its features in the context of the Socratic dialogue. Then, it presents some key points on the dream passage, and finaly, it sets out an interpretation of the Antisthenic philosophy that reveals relevant contacts with the Platonic approach. In this vein, we offer an hypothesis about the general sense of the dialogue and its way of comprehend the phenomenon of knowledge.

KEYWORD: Plato, Antisthenes, dream, knowledge, opinion.

\footnotetext{
RA

El corpus platónico combina obras señeras que se esfuerzan por ofrecer claves para comprender el sentido de esta línea de pensamiento con otras que despliegan argumentos cuyo propósito es confuso. Se trata de una conversación sobre el conocimiento que trastabilla después de varios intentos, enmarcada en una charla entre megáricos que desemboca en la lectura de un libro escrito por Euclides, cabeza de esta línea, sobre la base de supuestos relatos de Sócrates. ¿Por qué sería importante recordar este punto, como para que el personaje Euclides declare haber dedicado años a ajustar el texto? La historiografía ha explorado varias explicaciones, pero no nos interesa aquí esta presencia explícita a quien se le confía ficcionalmente el relato, sino una más elusiva, pero igualmente importante en el concierto de las discusiones de la
} 
época. Nos referimos a a Antístenes, condiscípulo de Platón que se opuso tanto a su línea como a la megárica por su profesión materialista y su concepción radicalmente distinta de la verdad.

En lo que sigue, nos detendremos en las fricciones entre estas filosofías de origen común, que incluyen no solo diferencias sino también puntos de contacto que ayudan a comprender en qué puede haber consistido en este momento formar parte del círculo socrático. En este marco, atendiendo a la discusión acerca del carácter aporético o euporético que jalona las discusiones recientes, consideraremos primero el abanico de posibles alusiones a otras filosofías socráticas en esta obra. En segundo lugar, analizaremos el pasaje del sueño, para examinar luego, en tercer lugar, los elementos

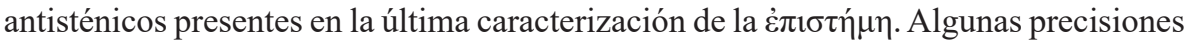
sobre el modo de entender la filosofía antisténica, y por tanto su posible conexión con el pasaje del sueño, muestran aspectos pertinentes para la evaluación de la dirección general del diálogo y su lugar en la epistemología platónica, subrayando la riqueza de las discusiones epistemológicas dentro del círculo.

\section{El horizonte de los socráticos en el Teeteto}

Euclides y Terpsión no están en Atenas sino en Mégara, alrededor del 369 a.C. y charlan de la desastrada mixtura de heridas y disentería que está cobrándose la vida de Teeteto, quien fuera en las épocas en que Sócrates vivía un joven promisorio con quien tuvo un diálogo tan memorable como para que Sócrates lo contara y Euclides se preocupara por ponerlo por escrito. Rápidamente la obra se centra en ese texto. En ella, tras analizar tres enfoques posibles respecto del conocimiento se está lejos de alcanzar una salida satisfactoria. El recorrido íntegro se ha considerado como un procedimiento purificatorio respecto de soluciones fallidas y por tanto propedéutico para una búsqueda con rendimientos efectivos, en la idea de que no puede haber en este diálogo una solución taxativa porque no se apela a la Teoría de las Formas, al mismo

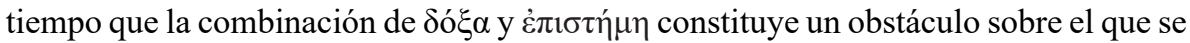
pretende advertir a quien pretenda emprender una búsqueda epistemológica fructífera. En este sentido, los problemas planteados serían resueltos en el Sofista, una suerte de "diálogo de las soluciones", donde el redimensionamiento en clave dinámica de las Formas y la explicitación de la relación entre ontología y lenguaje ofrece finalmente un modelo aceptable ${ }^{1}$.

Otras lecturas abogan por la compatibilidad del conocimiento con una $\delta$ ó $\xi \alpha$ que no implique un anclaje a la percepción sino a un tipo de juicio que, acompañado de justificación, constituiría una suerte de conocimiento no infalible, en conexión no tanto con el resultado final de la dialéctica, sino con el proceso de arbitrio de hipótesis y su admisión de elementos coherentistas, al menos como primera etapa del método.

Véase, por ejemplo, Cornford (1935, 142 ss.), Gerson (2003, 194, ss.), Sedley (2004, passim) y Ferrari $(2011,141 \mathrm{ss}$.$) .$ 
Con distintas variantes, estas líneas abogan por una aceptación de la caracterización

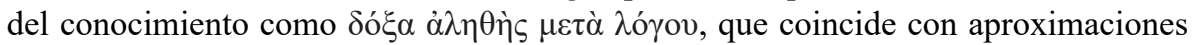
discutidas en la epistemología contemporánea. Si es así, la última presentación sería objetada solamente por sus fallas en la concepción acerca del $\lambda$ óyos, pero constituiría una contribución atendible que cimenta la investigación sobre una etapa sensible de la reflexión filosófica ${ }^{2}$. En última instancia, pasamos la mayor parte del tiempo lidiando con enunciados que están lejos de ser apodícticos o revelar su adecuación con el plano eidético.

Sin entrar en detalles aquí sobre estas cuestiones, partiremos de los componentes polémicos del enfoque que asume el diálogo, buscando acercarnos a la zona de tensión dialógica que lo enmarca. En rigor, el Teeteto es una región especialmente fértil para esta búsqueda. Al consultar el apéndice de los Socratis et Socraticorum Fragmenta dedicado a la revisar los loci platónicos que podrían aludir a las filosofías de sus condiscípulos, sobresalen en número República y Teeteto, habiendo entre ambos una diferencia clara de longitud, lo cual subraya la importancia de esta última obra como testimonio de los diálogos intra-socráticos ${ }^{3}$. Comencemos por mencionar brevemente las figuras cuya presencia se atisba en el Teeteto. En primer lugar, el diálogo es producto de una conversación entre Euclides y Terpsión, de modo que la obra está en manos de megáricos. Llama la atención, en efecto, que un diálogo con intereses epistemológicos esté guiado por un pensador asociado, en algunas interpretaciones, con la limitación radical de esta posibilidad y donde ser filósofo es, en algún sentido, denunciar la imposibilidad de erigir efectivo conocimiento ${ }^{4}$. La contaminatio entre $\delta o ́ \xi \alpha$ y $\dot{\pi} \iota \sigma \tau \eta \dot{\mu} \mu$ y la ausencia de

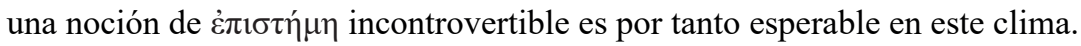

Por otra parte, este vínculo abre un abanico de llamativas asociaciones, donde sobresalen el tratamiento de la escritura, que contrasta con la aproximación de otros diálogos ${ }^{5}$, así como de la evaluación platónica de la erística, ya sea como una dialéctica desviada que se pretende condenar, como suele entenderse ${ }^{6}$, o como una versión del ह̌ $\lambda \varepsilon \gamma \chi 0 \varsigma$ socrático que Platón busca legitimar, tal como sostuvo M. Narcy en una lectura sugerente que acerca ambas filosofías ${ }^{7}$. En cualquier caso, la ausencia de alguna conclusión positiva puede responder al clima megárico que presta atención a este punto y podría constituir un indicio de que este grupo no es totalmente rechazado ni defendido, sino considerado a la vez valioso e insuficiente ${ }^{8}$.

En segundo lugar, es muy debatida pero sumamente persistente la sospecha de que

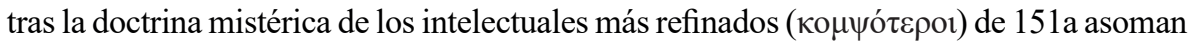

Entre otros Fine (1979), Burnyeat (1990) y Trabattoni (2010 y 2016).

SSR, I.H, 28 y 31.

Véase Muller (1985), Mársico (2013) y Gardella (2015).

Sobre la escritura, véase Rowe (2007).

Dorion (2000), Auffret- Rashed (2015, 31-48).

Narcy 2010.

Mársico 2011. 
tesis cirenaicas. Esta sugerencia de Schleiermacher, retomada por Dümmler a fines del s. XIX y reiterada en el s. XX por Mondolfo y Döring, con algunas oposiciones como las de Giannantoni y Tsouna, sigue despertando adhesiones, como las de Brunschwig y Zilioli ${ }^{9}$. Los cirenaicos serían, en esta perspectiva, neo-protagóricos imposibilidados de fundamentamentar epistemológicamente sus posiciones.

Hay que sumar a eso, por supuesto, la posible alusión a Antístenes que mencionamos. La raigambre anti-antisténica del Teeteto ha sido, en efecto, la más analizada, llegando a proponer que el diálogo está dirigido íntegramente a reflejar la polémica entre ambos condiscípulos, aunque con distinto grado de aceptación y plausibilidad ${ }^{10}$. Su influjo se ha visto en distintos pasajes del diálogo pertenecientes a las tres caracterizaciones del conocimiento, especialmente 152e-153d, 155e-156a, 161c-169b, 174a-175d, 187b-200c y 201-205e. Volveremos sobre esto enseguida.

Fuera de estos caminos más transitados, cabe notar que hay una segunda tríada de relaciones menos explorada que señala hacia Esquines, Simón y Fedón. En efecto, se constata una comunión de intereses con Esquines de Esfeto a propósito de la formación filosófica y los efectos de su abandono demasiado rápido, como en $150 \mathrm{e}-151 \mathrm{a}^{11}$. Y tampoco faltan vínculos con los testimonios que conservamos sobre Simón el zapatero, figura que explica para algunos la profusa utilización de ejemplos asociados con su técnica, como sucede también en otras obras. Simón sobrevuela igualmente la alusión al registro escrito en el proemio, en tanto Diógenes Laercio lo menciona como uno de los impulsores de la redacción de diálogos socráticos entendidos como práctica de registro intra-grupal de las conversaciones del maestro, precisamente como aquí dice Euclides que procedió en la redacción y ajuste del texto ${ }^{12}$.

Fedón de Elis, por su parte, igualmente integrante del círculo socrático y lider de un grupo con intereses y planteos distintos de los platónicos, resuena en segundo plano como figura especular de Euclides, ya que Platón pone en su boca otro de los relatos de diálogos capitales en lo que hace a la metafísica y la epistemología ${ }^{13}$. Se trata, por cierto, de las dos líneas más afines del platonismo y con quienes la doxografía testimonia relaciones amistosas, frente al horizonte de hostilidad abierta que lo opone a Aristipo y Antístenes. Esta división dentro del grupo da pie a la idea de un cierto acercamiento a las líneas megárica y elíaca, que por otra parte supieron históricamente combinarse. El punto es relevante como indicio de que no es necesario suponer siempre un enfrentamiento entre las diversas líneas que crecieron en el terreno socrático, lo

$9 \quad$ Schleiermacher $(1939,127)$; Dümmler $(1882,56)$; Mondolfo, (1953, 127-35), Döring (1988), Giannantoni (1990, IV.365 ss.), Tsouna (1998), Brunschwig (2001, 457-478) y Zilioli (2012, 46-74).

10 Véase Natorp (1903, 91-92), Joël (1901, 839), Raeder (1905, 280-283).

11 Véase Tarrant $(2012,159)$.

12 DL, II.123 y sobre Simón, véase Sellars (2003, 207-216).

13 Véase Boys-Stones (2004, 1-23), Mársico (2014, 79-99) y Rossetti (2015). 
cual es lógico, si es que alguna vez fueron un grupo que se frecuentaba habitualmente, aunque suele olvidarse ante el escenario de grandes rivalidades que también los atravesó.

En suma, el Teeteto revela ciertos rasgos identitarios del grupo, que no están cifrados en las soluciones sino en el tipo de problemas que los preocupan ${ }^{14}$. Resulta por tanto un espacio exploratorio de estas investigaciones que puede servir para señalar las limitaciones de estas líneas y la necesidad de una vía alternativa, configurando al mismo tiempo una declaración de su posición dentro del grupo. Salir, entonces, de estas barreras megáricas impuestas al terreno epistemológico, sin caer en el subjetivismo cirenaico que tanto se parece al protagorismo, sin perderse en el sistema de Antístenes es condición para pensar la cuestión del conocimiento en clave platónica. En este clima, además, se establece entre estas líneas una diferencia clara entre quienes están lo suficientemente cerca como para confiarle el relato y quienes solo serán aludidas entre líneas como sombras de otros o productores de sueños.

Un obstáculo en el estudio de este terreno radica, obviamente, en el estado fragmentario de las fuentes y en las dificultades y variantes de interpretación sobre las filosofías socráticas. Tras un despliegue progresivo de estudios desde el s. XVIII ${ }^{15}$, un viraje general usualmente asociado con los excesos especulativos de la historiografía decimonónica fue reforzado por la impronta de exégesis influidas por la reconstrucción argumental que condenó a priori toda lectura que atendiera a la dimensión de diálogo intragrupa ${ }^{16}$. La segunda mitad del s. XX alumbró trabajos que cimentaron, sin embargo, la vuelta a estos estudios. Exploraciones sobre el diálogo socrático, investigaciones locales sobre filosofías socráticas y finalmente la edición de G. Giannantoni que sentó bases filológicas firmes y una reconstrucción del estado de la cuestión funcionaron como plataforma para la multiplicación progresiva de trabajos de detalle muy alejados de los intentos iniciales. Es posible, entonces, en este nuevo contexto avanzar en un estudio menos afectado por desvíos especulativos y examinar alusiones intertextuales en el marco de la zona de tensión dialógica rica y compleja que nutrió los desarrollos de la filosofía del círculo socrático, con el objeto de recuperar la dimensión de posibles pasajes intertextuales que echan luz sobre el sentido interno de la obra platónica y sobre el clima intelectual general del período.

14 Véase Mársico (2018).

15 En el caso de Antístenes, en quien habremos de detenernos, tenemos noticia de estudios específicos desde comienzos del s. XVIII como el de Richter en 1724 y Crell en 1728, ambos siguiendo la línea de interpretación cínica que se desprende de Diógenes Laercio. Con la impronta de un cambio en la interpretación platónica en general producida por los cuatro volúmenes de Wilhelm Tennemann sobre el "sistema platónico" de 1792, junto a una visión de coherencia animada de elementos kantianos, llegó también un nuevo tipo de atención a la figura de Antístenes cristalizada en su obra histórica de 1799. Poco después, F. Schleiermacher amplió el espectro de análisis en sus estudios vertidos en los tomos de su Platons Werke, publicados entre 1804 y 1828 y su Die Philosophie der Griechen de 1839.

16 Véase, por ejemplo, Wilamowitz (1919). 


\section{El pasaje del sueño}

Entre los pasajes que más han llamado la atención por su potencial de análisis intertextual se encuentra sin dudas el pasaje del sueño. Este conocido texto ilustra

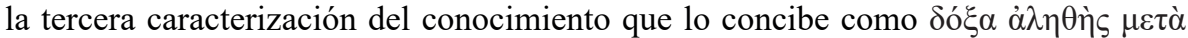

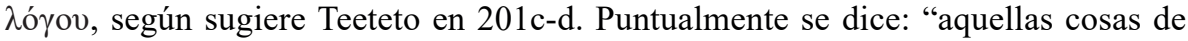

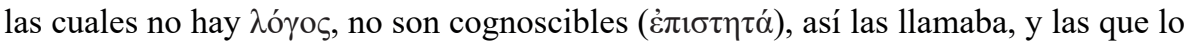
tienen, cognoscibles". El requisito de acompañamiento del lógos torna a las opiniones verdaderas $\dot{\varepsilon} \pi \iota \tau \eta \tau \alpha \dot{\alpha}, \hat{\alpha} \pi \alpha \xi \lambda \varepsilon \gamma o ́ \mu \varepsilon v o v$ que ha sido visto como indicio del reflejo de una tesis ajena, sugerida además por la mención de Teeteto de que ha escuchado esta idea de otros ${ }^{17}$, aunque podría tratarse también de la factura platónica de un adversario hipotético o una referencia a tesis propias previamente esgrimidas que hay que revisar. Esta última vía requiere aclarar la vinculación con el planteo del conocimiento como

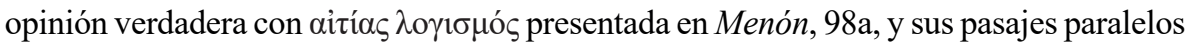
en Fedón, 76b y Banquete, 202a ${ }^{18}$. La evaluación de refutación o conservación de la tercera caracterización se ha ligado directamente con este punto, aunque, según sugeriremos, no deberían ser opciones incomposibles y la mejor alternativa exegética reside en mixturar ambas posibilidades.

La reacción inicial del personaje Sócrates señala una clave de lectura relevante, en tanto inquiere por el criterio para identificar y diferenciar el material discursivo que puede ser considerado explicativo y el que no, es decir qué es explicación, y por tanto conocimiento, y qué es doxa. Este criterio es el que finalmente servirá para evaluarla y en este punto anticipa el aspecto central del planteo que la caracterización no explicita desde el inicio, de modo que si bien no implica un error de principio, sufre de cierta vaguedad.

En consonancia con ello, Teeteto parece no conocer más que los rasgos generales de esta línea de pensamiento, dado que ante la requisitoria de explicitación

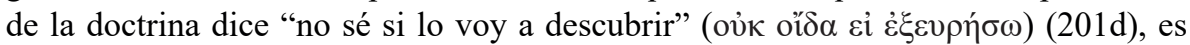
decir, no contempla exponer lo que ha escuchado sino reconstruir una fundamentación posible, lo cual recuerda la tarea hermenéutica sobre la tesis de Protágoras en el inicio del diálogo. No encontraremos, por tanto, descripción historiográfica, sino el examen con ánimo refutatorio de las posibles bases de algunas ideas esbozadas en la época. En rigor, Teeteto expone una opinión sin poder dar explicación de ella, lo cual resulta paradójico en el contexto de esta definición de conocimiento. Ante la duda de Teeteto, será Sócrates quien reponga los fundamentos. Este señalamiento de olvidos e inferencias sirve para poner distancia entre las distintas versiones, de modo tal que se habilita

17 La lista de hápax puede consultarse en Brancacci (2001:362-3). Véase además Narcy (1994, 366) y Ferrari $(2011,487)$.

18 Véase El Murr (2010, 135-156). 
alguna diferencia entre la teoría original, la versión en la que piensa Teeteto y la que expondrá Sócrates en la alusión a un sueño ${ }^{19}$.

Lo onírico había sido asociado en $158 \mathrm{~b}$ con la locura, como un ámbito en que "se forman opiniones falsas", y se alude al problema de la indiscernibilidad con la vigilia, de modo que "nuestra alma sostiene en sí misma, en cada uno de estos estados, que los juicios que forma, entonces, son los únicos verdaderos". Una teoría de origen onírico, por tanto, sugiere la imposibilidad de diferenciar estados y eso la vuelve ipso facto sospechosa. A Teeteto le viene a la mente ('́vvocĩv) como un recuerdo borroso y no puede responer al planteo de Sócrates: "dime cómo distinguía esas cosas que son

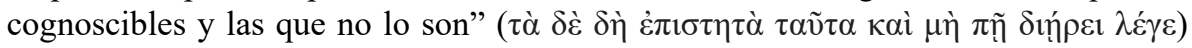
(201d). La imagen del sueño pone de relieve, entonces, la indiscernibilidad entre lo cierto y lo incierto, adelantando que la teoría será incapaz para establecer un criterio de demarcación. La objeción principal está lanzada, entonces, en el momento mismo en que se la asocia con lo onírico.

La fundamentación sugerida por Sócrates restringe la explicación a los compuestos, dejando los simples, $\tau \grave{\alpha} \pi \rho \tilde{\omega} \tau \alpha \sigma \tau o \imath \chi \varepsilon \tilde{\alpha} \alpha$, como objeto de nominación. De ellos no hay $\lambda$ ó $\gamma$ ○ $\mathrm{y}$ es solo por medio de su agregación que se ingresa en el nivel predicativo (201de) que conviene a ese plano. El pasaje recuerda la invitación a un $\delta \varepsilon v ́ \tau \varepsilon \rho \circ \varsigma \pi \lambda \circ \tilde{\varsigma} \varsigma$ en Fedón, 99c. En aquel contexto no se puede captar directamente las cosas y por ello hay que tomar la vía de las hipótesis, que suponen una estructura proposicional; aquí, de modo similar, para alcanzar conocimiento sería preciso enunciar el elemento en sí

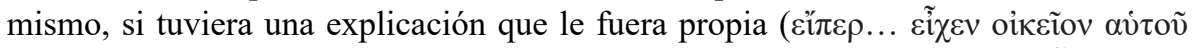

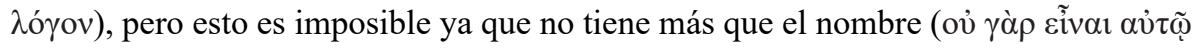

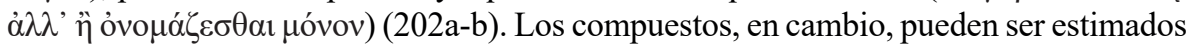
en un juicio verdadero.

La incomodidad con el planteo aparece enseguida, en tanto lo incognoscible resulta el material básico de lo cognoscible (202d-e) y el planteo íntegro adolecería, por tanto, de una asimetría que contraría condiciones básicas de fundamentación ${ }^{20}$. Para mostrar los inconvenientes de esta posición se acude al modelo lingüístico que estaría en la base de la teoría: las letras son a los simples como las sílabas a los compuestos. Se trata, en efecto, de un modelo que sirve para la técnica de la lecto-escritura y cualquier técnica en general, en tanto pueden desentenderse de la fundamentación última y en ese sentido contrasta con las pretensiones de la filosofía. Mirando a lo concreto, como las técnicas del nivel dianoético en el símil de la línea, puede partir de elementos axiomáticos sin afectar su status epistémico, pero claramente se renuncia con esto a una respuesta última sobre la naturaleza del conocimiento. En rigor, este punto bastaría para poner en jaque la pretensión de esta concepción de la $\dot{\varepsilon} \iota \iota \tau \eta \dot{\mu \eta}$, pero el texto avanza para

19 Véase Narcy (2010). Sobre estrategias para tratar las tesis de los adversarios, Mársico, 2005.

20 Es la tesis, por ejemplo, que sostiene Fine (1979: 369 ss.). 
mostrar un mayor grado de inconsistencia, lo cual alimenta la idea de una teoría rival que Platón tiene interés en impugnar hasta las últimas consecuencias.

Esta reconstrucción, en efecto, conduce a un dilema: la explicación de la sílaba requiere la enumeración de las letras componentes, de modo que la sílaba equivale a las letras o forma una entidad distinta. En el primer caso, para que haya conocimiento no debería haber asimetría de cognoscibilidad y por tanto se requeriría conocimiento de los elementos (203d), y en el segundo caso, si las sílabas son una nueva entidad básica resultarían tan incognoscibles como las letras y carecerían, por tanto, de explicación (205c-e). El corolario de este recorrido implica que "el género de los elementos tiene un conocimiento mucho más claro y decisivo que el del compuesto para la perfecta aprehensión de cada objeto de estudio" (206b), por lo cual cualquier teoría apoyada en la incognoscibilidad de los elementos constituye "una broma" (206b). La conversión del sueño en broma muestra hasta dónde se busca hundir esta opción epistemológica.

\section{Rastros de la teoría antisténica}

El pasaje del sueño, como dijimos, guarda varias posibles alusiones a Antístenes. Este condiscípulo sobresale en la doxografía helenística por las noticias sobre sus enfrentamientos con Platón y por los datos sobre una obra cuantiosa que habría inspirado una vertiente importante de la filosofía helenística de cuño cínico-estoica. Sus posiciones, posiblemente influidas por la filosofía gorgiana ${ }^{21}$, configuran una suerte de inversión de los postulados de este sofista en su Tratado del no ser, "nada es, si es no puede ser conocido y si es conocido no puede ser transmitido", para fundar un objetivismo que considera al lenguaje como un elemento con adecuación plena respecto de lo real, lo cual lo lleva a renegar del discurso falso. Esta tesis es a menudo menospreciada por sus aires erísticos, pero constituye un elemento de peso en la tradición posterior vinculada con la persistencia de la línea que cifra la correlación entre el lenguaje y lo real en una clave onomástica ${ }^{22}$. En buena medida, esta disidencia explica el mayor punto de oposición con la perspectiva platónica.

Veamos esto con mayor detalle. Invirtiendo el planteo gorgiano Antístenes sostiene una metafísica corporeísta ${ }^{23}$ de adecuación plena al lenguaje concebido como sumatoria de nombres. Así, "el que dice, dice algo, el que dice algo, dice lo que es y

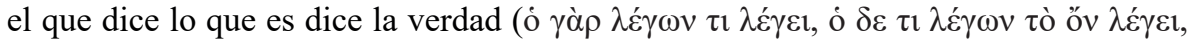

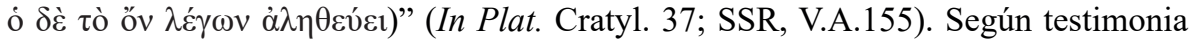

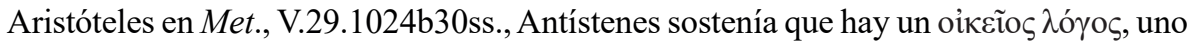
para cada cosa ( $\check{\varepsilon} v \dot{\varepsilon} \varphi$ ’ $\dot{\varepsilon} v o ́ \varsigma)$, de modo que “no es posible contradecir ni, prácticamente, decir falsedad". El neutro $\check{c} v$, injustificable desde el punto de vista gramatical, puede responder, como se ha sugerido, a la cita de una categoría del pensamiento antisténico

Mársico, 2013.

Simplicio, in Aristot. categ., 208.28-32 (= SSR, V.A.149). 
que referiría precisamente al óvo $\mu \alpha$ de cada cosa y quedaría, por tanto, al margen de toda combinación ${ }^{24}$. También podemos pensar en el neutro $\pi \rho \tilde{\alpha} \gamma \mu \alpha$, en referencia a las entidades mundanas, que quedan referidas en la nominación, haciendo del lenguaje una mostración de las cosas. Los desarrollos lingüísticos estoicos, en una línea que reclama paternidad antisténica, apoyaría esta idea.

Por otra parte, en Met. VIII.3.1043b23 ss. (= SSR V A 150), Aristóteles agrega un dato importante sobre la operatoria de los óvó $\mu \alpha \tau \alpha$, cuando dice, tras tratar a los antisténicos de incultos ( $\dot{\alpha} \pi \alpha i ́ \delta \varepsilon v \tau o r)$, que sostenían que "no es posible definir el qué

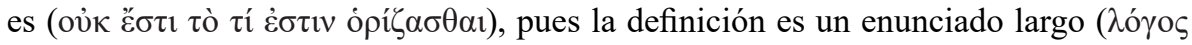
$\mu \alpha \kappa \rho o ́ \varsigma)$, aunque es posible enseñar ( $\left.\delta \_\alpha ́ \xi \alpha \imath\right)$ a otros cómo es (pốón esti) una cosa". $\mathrm{La}$ "longitud" implica precisamente su complejidad, que contrasta con la simplicidad de los nombres. Esto implica que el Sócrates antisténico no preguntaba “ti esti x", sino "poîon esti x".

Para aclarar este punto Aristóteles recurre a un ejemplo: "respecto de la plata,

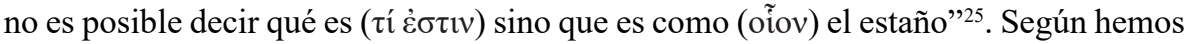
propuesto en otra oportunidad, esto configura el aporte más relevante de la filosofía antisténica, en tanto implica el desarrollo de una proto-teoría de campos semánticos, de acuerdo con la cual se parte del dato básico de elementos simples onomásticos autopatentes frente a los cuales hay que explorar con la guía del $\pi$ oĩó $\tau \imath$ la red de relaciones que los une hasta reconstruir la trama de relaciones entre entidades que configuran lo real. Dada esta correlación, el filósofo antisténico no se desvela ante la pregunta por el acceso a este plano, porque el lenguaje revela a cualquier hablante nativo las claves para emprender la búsqueda. La diferencia entre el filósofo y el resto radica en la capacidad para reconocer esta relación y avanzar en un conocimiento sistemático del lenguaje que le depara como resultado de su pericia hermenéutica un conocimiento progresivo

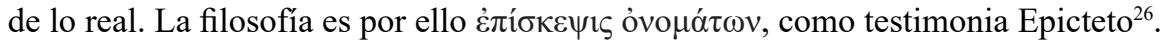

En nuestra interpretación de la filosofía antisténica el plano predicativo asociado con la definición no tiene aquí cabida y el nivel discursivo que establece relaciones reposa, como en el modelo platónico del sueño, en elementos primarios que no requieren explicación y cuyo develamiento adviene por la red de vínculos semánticos operada por el filósofo en su tarea de comprensión de lo real. La definición, por tanto, no suma nada y oscurece, al contrario, un tipo de comprensión que se ajusta precisamente al modo en que los hablantes nativos comprenden su lengua.

Este punto es sintetizado por Aristóteles inmediatamente al decir: "de modo que sólo puede haber definición y enunciado de una clase de sustancia, a saber, de la compuesta, sea sensible, sea inteligible; pero no de los componentes primarios de que se constituye esa sustancia" (Met. VIII.3.1043b23 ss. (= SSR, V. A.150)), punto que remite directamente al núcleo de la teoría del sueño y que señalaría el punto que

$24 \quad$ Véase Cordero (2001, 323-344).

25 Véase además Porfirio (SSR, VA187-9).

26 Diss. I.17.102 (= SSR, V.A.160). 
despierta la polémica entre ambas líneas socráticas ${ }^{27}$. En rigor, esta afirmación traduce en términos aristotélicos el corolario del planteo, como es claro a partir de la distinción entre sustancia sensible e inteligible, que no tiene sentido en el contexto del corporeísmo antisténico donde para existir hay que ser algo cualificado ( $\pi$ oĩó $\tau \imath$ ).

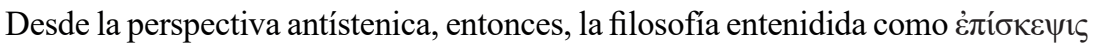
ỏvo $\mu \alpha ́ \tau \omega v$ reconstruye campos semánticos que reflejan el "mapa de lo real", de modo que las estructuras predicativas copulativas no son más que la expresión de propiedades, es decir instanciaciones del $\pi$ oĩóv $\tau$, tanto en casos como "el caballo es blanco" o "Sócrates está en Atenas", como en "Sócrates es hombre", a la manera en que Aristóteles reconoce en Categorías, 3b15, el vínculo entre sustancia segunda y cualidad. Las definiciones esconden la expresión de propiedades, del mismo modo que las Formas platónicas eran vistas por Antístenes en el Satón como propiedades hipostasiadas ${ }^{28}$. Desde su perspectiva, Platón proyecta realidades estables como respaldo ontológico para las definiciones, de un modo innecesario si se recurre al parámetro lingüístico y la guía del poî́n ti que ofrece, como alternativa, una red semántica con correlato ontológico.

Como sucede en otros casos, esta no es la única reconstrucción posible de la posición antisténica y las variantes impactan directamente en la evaluación del contacto con el pasaje del Teeteto. En la interpretación de Brancacci, que ha dado enorme impulso a los estudios sobre esta filosofía, se encuentra un espacio para un tipo de

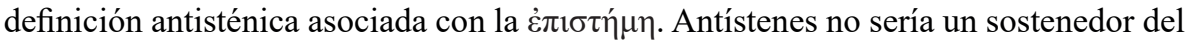
criterio onomástico y de una proto-teoría de campos semánticos, sino un precursor de

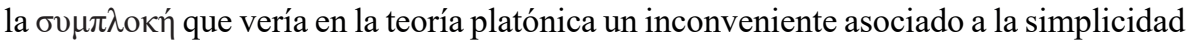
de las Formas. Los elementos primarios en este esquema no serían los óvó $\mu \alpha \tau \alpha$ y su correlato en cuerpos cualificados, sino las Formas platónicas, que quedarían de este modo fuera del campo del conocimiento entendido precisamente como $\delta$ ó $\xi \alpha \dot{\alpha} \lambda \eta \theta \grave{\eta} \varsigma$ $\mu \varepsilon \tau \grave{\alpha} \lambda$ ó$\gamma o v^{29}$.

En nuestra perspectiva, resulta poco claro que, si efectivamente se trataba de un argumento antiplatónico que tenía como objetivo cuestionar la teoría de las Formas, Aristóteles adujera la pregunta $\pi$ oĩóv $\tau \imath$ y el ejemplo de la plata, que constituye precisamente un ejemplo que no apela a la definición y recurre a un objeto sin rasgos del tipo de simplicidad que afectaría a las Formas. Por otra parte, la crítica del Satón parece haber consistido, como dijimos, en que las Formas son cualidades hipostasiadas, como la caballeidad ${ }^{30}$, pero no hay rasgos que hagan de la simplicidad un elemento pernicioso, especialmente cuando la teoría antisténica insiste en nombres de unicidad

27 Sobre los problemas textuales del pasaje, véase Brancacci (2001). Sobre la relevancia de la posición de Antístenes para el planteo aristotélico sobre los simples, véase H. Inverso, 2011.

28 SSR, V.A.149.

29 Véase Brancacci (2001: 376-7).

30 Véase Cordero (2001: 323-44). 
similar, solo que sin el correlato ontológico de carácter eidético que deja al mundo circundante en la categoría de copia.

La investigación de los nombres con la guía de la pregunta $\pi$ oĩó $\tau \tau$ ofrece ejemplos en numerosos testimonios conservados, como los análisis de pasajes homéricos ${ }^{31} \mathrm{y}$ el análisis de las virtudes que transmite Jenofonte en Memorabilia, IV. $5^{32}$. Esta matriz de análisis permite, según dice Aristóteles, la enseñanza, que supone un carácter epistémico que no apela a la definición. Si entendemos la distancia entre ambos autores como una cuestión asociada al status del lenguaje de correlato estricto en el caso de Antístenes y de correlato variable en el caso de Platón y al criterio onomástico para el primero y predicativo para el segundo el pasaje del sueño cobra mayor sentido.

En efecto, si Antístenes hubiese apelado a definiciones, lo que Platón describe como enumeración de elementos resulta oscuro y hay que colegir, en efecto, que no solo

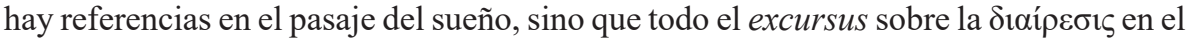
Sofista constituye una referencia a la metodología antisténica ${ }^{33}$. Ambos autores deberían para ello haber estado mucho más cerca de lo que sugieren las fuentes. Si no es así, la enumeración de elementos puede haber sido un modo en que Platón comprendía el método de análisis semántico, que a primera vista puede dar la sensación de un listado, como sucede, por ejemplo, con el enjambre de virtudes en Menón, 71e-72a.

Una lectura de este tipo tiene, por otra parte, ventajas de economía teórica, ya

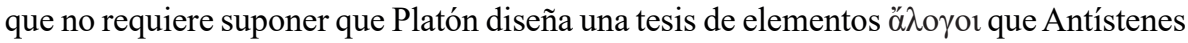
nunca propuso ${ }^{34}$ y luego Aristóteles interpreta literalmente para atribuirla sin más a Antístenes. Por el contrario, sin la introducción de una teoría de la definición antisténica, Platón estaría retratando críticamente pero sin distorsiones mayores una posición rival y Aristóteles sintetizaría el núcleo de la disidencia.

Probablemente ambos socráticos compartían la preocupación por la caracterización del $\lambda$ ó $\gamma$ ○ y su relación con el pensamiento y el lenguaje, pero colisionaban en el modo de abordar el problema. El texto sigue poniendo de relieve precisamente esta noción, respecto de la cual se analizan tres opciones, relevantes todas para el análisis del vínculo con la posición antisténica y su refutación. La primera en 206d implica "hacer manifiesto

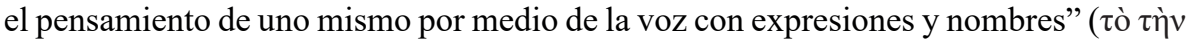

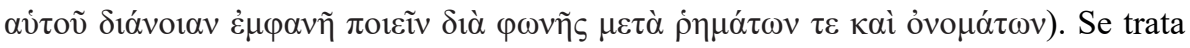
del punto de partida de la epískepsis onomáton, en que un sujeto en pleno dominio del lenguaje explora su estructura y obtiene con ella rendimientos en el conocimiento de lo real que es su correlato. Sin embargo, sin esta condición de correlato, que la posición de Platón no concede salvo como resultado del procedimiento dialéctico que distinga IX.106 (SSR, V.A.189), IX.525 (SSR, V.A.190).

32 Sobre este vínculo, véase Maier 1943, 68-70), Decleva Caizzi (1966, 72-73, Chroust (1957, 101-134) y Brancacci (1990, 138-144).

33 Brancacci (2001:372).

34 Brancacci (2001:373).
} 
el discurso verdadero del falso, esta manifestación es indistinguible de la opinión, de modo que desde esta perspectiva la posición antisténica queda presa íntegramente en ese plano como mero análisis del sentido común.

La segunda caracterización en 208b-c implica la operación con elementos, pero es entendida como un caso de opinión verdadera cuya explicación no alcanza para ser considerada saber. El ejemplo gramatical de pericia para la ortografía de un nombre que puede no ser generalizada ha sido mayoritariamente entendido como un requisito de captación de la lógica del elemento en diferentes combinaciones ${ }^{35}$. De este modo, la descripción constitutiva puede no implicar conocimiento. Esta crítica cobra sentido si el horizonte de discusión es primariamente la teoría de Antístenes, que identifica el conocimiento con la comprensión de regiones onto-semánticas a partir del análisis lingüístico.

Desde la perspectiva de Platón, Antístenes parte de elementos sin explicación (el oíkeĩo como si se tratara de una gramática de lo real. La crítica que postula es que con este método se alcanzan a lo sumo descripciones locales con un status indiferenciable de la opinión verdadera, dado que en realidad no hay en todo el planteo una instancia de fundamentación. En efecto, el conocimiento advendría con la explicación, pero una descripción local sin marco alguno más abarcativo no podría nunca alcanzar este plano.

En la tercera opción, finalmente, el $\lambda$ ó $\gamma o s$ implica la identificación de "la diferencia

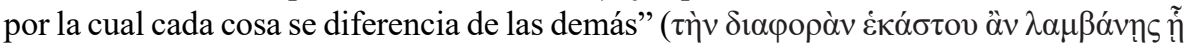

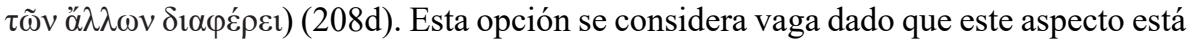
presente en procedimientos, como el reconocimiento de la individualidad de Teeteto en 209a-d, que pertenecen al plano de la dóxa, o debe entonces imponerse un requisito epistémico de modo que el saber sería "una opinión correcta acompañada de saber"

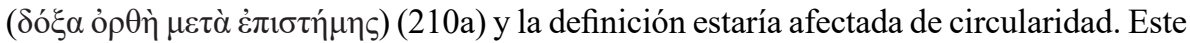

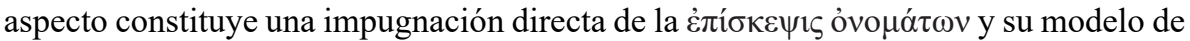
$\pi$ oĩóv $\tau$. En efecto, si nos remontamos al ejemplo de la plata del testimonio aristotélico de Met. VIII.3, su explicación residiría en la descripción exhaustiva de sus relaciones, de modo tal que quedaría explicada por rasgos del tipo "es como el estaño" (oíov

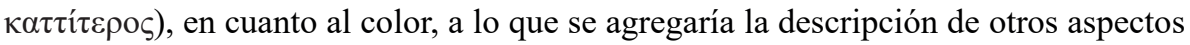
del tipo "como el oro" en brillo, "como el cobre" en dureza, etc.

Si el análisis es exhaustivo, ofrece el mapa de vínculos de una región ontosemántica. Desde la perspectiva platónica, sin embargo, esta descripción local puede hacerse enteramente en el nivel de la opinión. Para decirlo con terminos fenomenológicos: donde Antístenes sostiene estar efectuando juicios apodícticos amparados en la comprensión inmediata de los oỉęĩ ỏvó $\mu \alpha \tau \alpha$ en una suerte de reducción lingüística de adecuación plena, Platón solo ve una exploración mundana que describe en el mejor de los casos el modo en que un sujeto comprende su mundo circundante. Para que 
surja conocimiento en este contexto debería proveerese otra calidad en el producto de la investigación, pero Antístenes, con su punto ciego en elementos incognoscibles, no está en condiciones de asegurarla.

Las tres opciones, entonces, constituyen intentos de acorralar a la posición antisténica, cuya síntesis podría ser el análisis de las expresiones del lenguaje con que opera el sujeto a los efectos de describir exhaustivamente sus elementos y detectar las diferencias específicas de cada uno. Frente a ello, Platón plantea que no hay explicación en la manifestación del pensamiento, ni en la enumeración de elementos, ni en la identificación de diferencias entre ellos, en lo que configura una oposición taxativa a todos sus aspectos.

\section{Corolarios}

Este trabajo de revisión de opiniones se afirma cerrando el diálogo, libera mayéuticamente de falsas creencias y prepara para nuevas exploraciones. Ahora bien, volviendo a nuestra preocupación inicial, ¿cuán nuevos serán estos análisis y cuánto resiste de la última

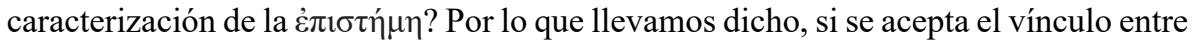
el pasaje del sueño con su interpretación crítica y la filosofía de Antístenes entendida como una proto-teoría de campos semánticos, las oposiciones tradicionales varían.

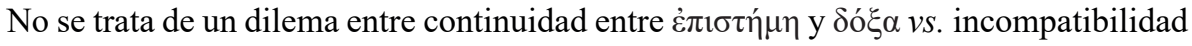
radical, sino de una estrategia platónica para mostrar que los parámetros antisténicos no salen nunca del plano de la opinión y por tanto la caracterización de $\delta$ ó $\xi \alpha \dot{\alpha} \lambda \eta \theta \grave{\eta} \varsigma$ $\mu \varepsilon \tau \grave{\alpha} \lambda$ ó $\gamma o v$ no puede aceptarse nunca si es pasible de una interpretación de ese tipo.

Es posible, entonces, acercar posiciones entre quienes conciben al Teeteto como un diálogo aporético y quienes consideran que hay elementos de la última caracterización que encuentran lugar en la filosofía platónica, pero por motivos distintos. Su aporeticidad reside en que, en el contexto de las polémicas intra-grupales, amparado en un relato "megarizante" que se solaza en la refutación, la caracterización antisténica es vencida y no puede reclamar status epistémico, precisamente porque se advierte que en un esquema de ese tipo se produce la contradicción de que el conocimiento es primariamente $\delta$ ó $\xi \alpha$ con un agregado secundario. El conocimiento, por tanto, no puede ser $\delta$ ó $\xi \alpha \dot{\alpha} \lambda \eta \theta \grave{\eta} \varsigma$ $\mu \varepsilon \tau \grave{\alpha} \lambda \lambda_{\text {ó }} \mathrm{v}$ bajo las condiciones de fundamentación examinadas y entendiendo el $\lambda$ ó $\gamma$ o $̧$ en esos términos. No hay, en rigor, una admisión de conocimiento no infalible,

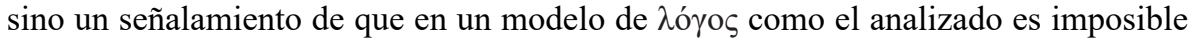
trascender lo doxástico y debe por tanto proseguir la exploración.

Lo que sobrevivirá, entonces, es la conciencia de la importancia de encontrar una caracterización del $\lambda o ́$ ó lejos del criterio onomástico, desplegando un criterio predicativo que conviene a la búsqueda dialéctica de cuño platónico, donde la explicación efectivamente libere a la enunciación de su carácter doxástico. Si algo habrá de sobrevivir de la $\delta$ ó $\xi \alpha$, es una versión deflacionada hasta el punto de ser simplemente una enunciación guiada por la dialéctica, es decir, de un lenguaje orientado por la ontología, y por tanto puesto al servicio de lo noético, según las recomendaciones señeras que cerraban el Crátilo. 


\section{Referencias bibliográficas}

Auffret, T.-Rashed, M. (2015), “Observations sur le Prologue du Théétète”, en V. Gysembergh - A. Schwab, eds., Le travail du Savoir. Philosophie, sciences exactes et sciences appliquées dans l'Antiquité. Trier: Wissenschaftlicher Verlag Trier.

Boys-Stones, G. R. (2004), "Phaedo of Elis and Plato On the Soul", Phronesis 49: $1-23$.

Brancacci, A. (1990), Oikeios logos. La filosofia del linguaggio di Antistene. Napoli: Bibliopolis.

(2001), "Antisthène, la troisième définition de la science et le songe du Théétète", en G. Romeyer-Dherbey - J. Gourinat, eds., Socrate et les Socratiques. Paris: Vrin, pp. 351-380.

(2010), “Aristotele e la dottrina del sogno del Teeteto", en G. Mazzara - V. Napoli, eds., Platone. La teoria del sogno nel Teeteto. Sankt Augustin: Academia.

Brunschwig, J. (2001), "La théorie cyrénaïque de la connaissance et le problème de ses rapports avec Socrate”, en G. Romeyer-Dherbey, Socrate et les socratiques. Paris: Vrin.

Burnyeat, M. (1990), The Theatetus of Plato. Indianapolis-Cambridge: Hackett.

Chroust, A. (1957), Socrates. Man and Myth. London: Routledge.

Cordero, N. (2001), "L'interpretatio antisthénienne de la notion platonicienne de 'forme' (eidos, idea)", en M. Fattal (ed.), La philosophie de Platon. Paris: L'Harmattan.

Cornford, F. (1935), Plato's Theory of Knowledge. London: Kegan Paul.

Crell, L. (1728), Programma de Antisthene Cynico. Leipzig,

Decleva Caizzi, F. (1966), Antisthenis Fragmenta. Milano-Varese: Istituto Editoriale Cisalpino.

Döring, K. (1988), Der Sokrastesschüler Aristipp und die Kyrenaiker. Mainz: Akad. Wiss. U.d. Literatur.

Dorion, L. (2000), “Eythydème et Dionysodore sont-ils des Mégariques?”, Proceedings of the V Symposium Platonicum. Sankt Augustin: Academia, pp. 35-50.

Dümmler, F. (1882), Antisthenica. Halle: Heidel.

El Murr, D. (2010), “Desmos et logos: de l'opinion droite à la connaisance, ou ce que le Ménon apporte au Théétète", en G. Mazzara - V. Napoli, eds., Platone. La teoria del sogno nel Teeteto. Sankt Augustin: Academia.

Ferrari, F. (2011), Platone, Teeteto. Milano: BUR.

Fine, G. (1979), "Knowledge and Logos in the Theaetetus", Philosophical Review 39: 366-397.

Gardella, M. (2015), Las críticas de los filósofos megáricos a la ontología platónica. Buenos Aires: Rhesis. 
Gerson, L. (2003), Knowing Persons: A Study in Plato. Oxford: OUP.

Giannantoni, G. (1990), Socrates et Socraticorum Reliquiae. Napoli: Bibliopolis.

Hardy, J. (2001), Platons Theorie des Wissens in Theaitet. Göttingen: Vandenhoeck \& Ruprecht.

Ioppolo, A. (1999), Introduzione a Platone, Teeteto. Roma-Bari: Laterza.

Joël, K. (1901), Der Echte und der Xenophontische Sokrates. Berlin: Gaertners.

Maier, H. (1943), Socrate. La sua opera e il suo posto nella storia. Firenze: La Nuova Italia.

Mársico, C. (2005), "Antístenes y la prehistoria de la noción de campo semántico", Nova Tellus 23.2.

(2013), Filósofos socráticos I. Testimonios y fragmentos. Megáricos y Cirenaicos. Buenos Aires: Losada.

(2014), Filósofos socráticos II. Testimonios y fragmentos. Antístenes, Fedón, Esquines y Simón. Buenos Aires: Losada.

(2017), Platón, Alcibiades. Buenos Aires: Miluno.

(2018), "About the common grounds of Socratic philosophies: the anthropological core", Acta Classica 62.

Mondolfo, R. (1953), “I Cirenaici e i 'raffinati' nel Teeteto platonico”, Rivista di filosofia 44; pp. 127-35

Muller, R. (1985), Les Mégariques. Fragments et témoignages. Paris: Flammarion.

Narcy, M. (1995), Platon, Théétète. Paris: Flammarion.

(2010), "Socrate et Théétète font-ils le même rêve?", en G. Mazzara - V. Napoli, eds., Platone. La teoria del sogno nel Teeteto. Sankt Augustin: Academia.

Natorp, P. (1903), Platons Ideenlehre. Leipzig: Duerr.

Nehamas, A. (1989), “Episteme and logos in Plato's Later Thought”, en P. Anton -A. Preus, eds., Plato, Essays in Greek Philosophy III. New York: SUNY Press.

Raeder, H. (1905), Platons philosophische Entwicklung. Leipzig: Teubner.

Richter, G. (1724), Dissertatio historico-philosophica de vita, moribus ac placitis Antisthenis Cynici, Jena.

Rossetti, L. (2015), “Plato's Zopyrus (and Socrates' Confidences)”, en U. Zilioli, ed., From the Socratics to the Socratic Schools. London: Routledge.

Rowe, C. (2007), Plato and the Art of Philosophical Writing. Cambridge: CUP.

Schleiermacher, F. (1828), Platons Werke. Berlin: Reimer.

(1839), Dialektik, Berlin, Reimer.

Sedley, D. (2004), The Midwife of Platonism, Text and Subtext in Plato's Theaetetus. Oxford: OUP.

Sellars, J. (2003), "Simon the Shoemaker and the Problem of Socrates", Classical Philology 98.3: 207-216. 
Tarrant, H. (2012), "Improvement by love: From Aeschines to the Old Academy", en M. Johnson - H. Tarrant, eds., Alcibiades and the Socratic Lover-Educator. London: Bristol Classical Press.

Tenneman, W. (1799), Geschichte der Philosophie. Leipzig: Barth.

(1792), System der Platonischen Philosophie. Leipzig: Barth.

Trabattoni, F. (2010), "Fondazionalismo o coerentissimo? In margine alla terza definizione di epistle del Teeteto", en G. Mazzara - V. Napoli, eds., Platone. La teoria del sogno nel Teeteto. Sankt Augustin: Academia. Press. (2016), Essays on Plato's Epistemology. Leuven: Leuven University

Tsouna, V. (1998), The Epistemology of the Cyrenaic School, Cambridge.

Willamowitz, U. (1919), Platon. Berlin: Weidman.

Zilioli, U. (2012), The Cyrenaics. London: Acumen. 